\title{
Paper 54
}

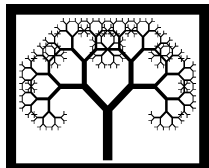

\section{Aerodynamic Loads in Open Air of High Speed Trains: Analysis of Experimental Data}

\author{
M.M. Caccialanza, D. Rocchi, P. Schito, C. Somaschini \\ and G. Tomasini \\ Dipartimento di Meccanica \\ Politecnico di Milano \\ Italy
}

\begin{abstract}
The homologation of high-speed trains is a demanding and expensive procedure. In particular, the evaluation of train slipstream according to the standard TSI, 2008 is divided in two different test programmes: one concerning the workers at the trackside and the other studying the passengers standing on the platform. This paper presents some slipstream measurements performed on three high speed trains and a comparison between them. The objective is to investigate the slipstream on the platform and relate it to the flow measured at the trackside at the same height with respect to the top of the rail. This topic is currently under revision by the commission in charge of the TSI standard. Interesting evidence concerning the improvements of the aerodynamic performance of new-generation trains are highlighted.
\end{abstract}

Keywords: aerodynamics, high speed train, slipstream velocities, gusts, technical specifications, interoperability.

\section{Introduction}

As described in the TSI HS RST Standard [1], the homologation procedure for highspeed trains requires specific field tests to evaluate the aerodynamic loads on track workers at the line side and on passengers on a platform. In fact, the slipstream velocity of a train can have an effect on trackside workers, waiting passengers, pushchairs, wheelchairs, trolleys and other objects on the platform.

Over the last years, a number of studies were performed to analyse the problem. Slipstream effects can be evaluated by experimental or numerical approaches. In general, CFD numerical analyses need experimental data to validate the code but, after this verification, they allow to have a complete vision of the flow around the train and to study the effects of different parameters. The numerical analysis is particularly useful to analyse the influence of those parameters which can not be 
easily modified during the experimental tests as, for example, the nose shape [2], the height of platform [3], the natural cross wind speed [4], etc.

As far as the experimental methods are concerned, tests can be performed at full scale [5], [6], [7] or at model scale ([8], [9], [10]). In [7], the most important measurement parameters that influence the slipstream of a train are pointed out (and then accounted for in the TSI standard), such as the position of the measurement point (height above ground and transversal distance from the train) and the occurrence of the peak gusts (during the train passage or after in the wake). In the same paper, a comparison between experimental tests carried out on reduced scale moving model and full-scale measurements on high-speed train and on freight trains is presented: the authors conclude that the results obtained from measurements with scale moving models are in good agreement with the full scale measurements and reproduce all the important flow features.

More recently, full-scale tests performed on different EU trains as part of the EUfunded AeroTRAIN project have been compared and analysed in terms of ensemble averages in [5] and gust values in [6]. The fundamental aim of this work is to reduce the complexity of the current technical specifications for interoperability (TSI) testing methodology, which prescribes two different tests for open air and platform aerodynamic loads evaluation, each one requiring twenty full-scale independent measurements of the air speed in the plane when the train is passing. The most important conclusion of the two papers is that, for a specific train, trackside measurements are not significantly different from the platform measurements and, as a consequence, the trackside measurements, at different heights, could be sufficient for the evaluation of the train slipstream.

In this paper, the results of full-scale slipstream measurements carried out in open air and at platform with the three high-speed trains running on the Italian Railway Network are presented and compared with the data reported in the previous papers.

In the first part, the effects of the train aerodynamic and geometrical properties on the air speed are analysed both in terms of average and gust values. In the second part, the effect of the measurement point height on the slipstream is studied considering the two quotes prescribed by the TSI standard, which are respectively $0.2 \mathrm{~m}$ and $1.4 \mathrm{~m}$ from the Top Of Rail (TOR). Finally, the third part presents a comparison between tests with and without platform, in order to understand if the platform influence is negligible, as concluded in [6].

Thanks to the high number of recorded data (greater than twenty for each class), the performed statistical analyses are consistent and the different trains are compared in terms of both space histories of the mean value and the most significant percentiles as well as synthetic parameters (gust values).

\section{Data presentation and set up of the tests}

The results presented in this work have been organized in the database described by Table 1 . The ensembles are constituted by different runs of the three actual Italian high speed trains (Figure 1), measured in different experimental campaigns: the first two measurements have been conducted along a straight section at trackside (or equivalently, in an open-field environment), but varying the anemometer height; the 
last was measured in the presence of a platform, whose height is $0.25 \mathrm{~m}$ with respect to the TOR. All the considered runs comply the requirements of the TSI HS RST [1] normative. Table 1 reports also the nominal train speed during the test. As shown by Zhang in [4] the linear proportional relation between the train speed and the slipstream velocities allows comparing tests performed at different speeds, using the train speed itself as the scaling factor.

\begin{tabular}{|c|c|c|c|}
\hline Site & Open Field & Open Field (2) & Platform \\
\hline $\begin{array}{c}\text { Anemometers height } \\
\text { (above the top of the rail) }\end{array}$ & $0.2 \mathrm{~m}$ & $1.4 \mathrm{~m}$ & $1.4 \mathrm{~m}$ \\
\hline Nominal test speed & $300 \mathrm{~km} / \mathrm{h}$ & $300 \mathrm{~km} / \mathrm{h}$ & $200 \mathrm{~km} / \mathrm{h}$ \\
\hline
\end{tabular}

\begin{tabular}{|c|c|c|c|}
\hline Train (length) & \multicolumn{3}{|c|}{ \# runs } \\
\hline Train A (200 m) & 21 & $33^{*}$ & 28 \\
\hline Train B (200 m) & 24 & 36 & 20 \\
\hline Train C (330 m) & 57 & 51 & n.a. \\
\hline
\end{tabular}

* For these runs the nominal speed of Train A was $250 \mathrm{~km} / \mathrm{h}$.

Table 1: The experimental database.

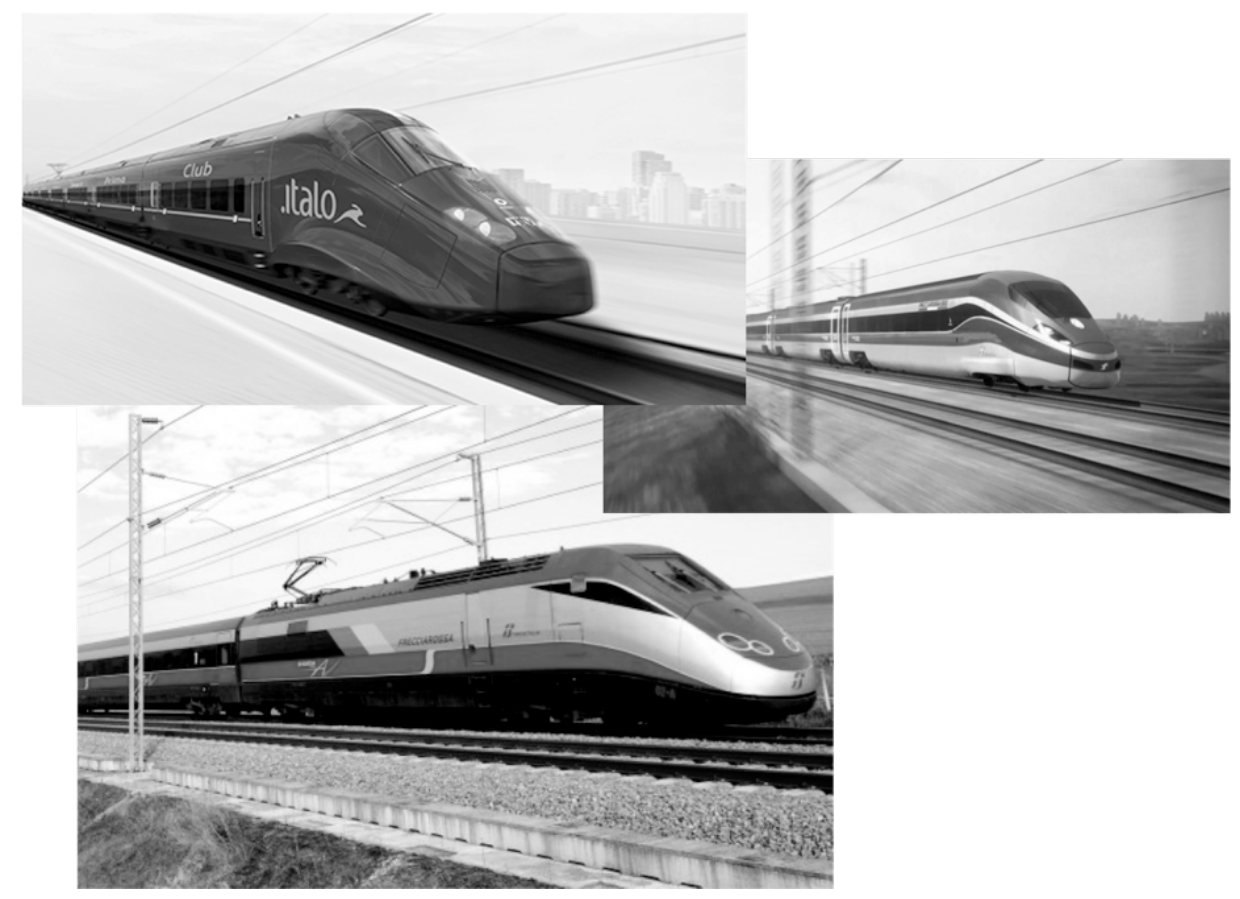

Figure 1: Actual Italian high-speed trains.

The slipstream experimental tests were performed on the Italian High Speed Line Torino-Milano (max speed $300 \mathrm{~km} / \mathrm{h}$ ), precisely at PC Recetto. The setup used for the assessment of slipstream in the Open Field campaign can be observed in Figure 2: a total of 4 ultrasonic anemometers (Gill Instruments Windmaster 1590 pk020) were placed along the track, with a distance between them larger than $20 \mathrm{~m}$ (Figure 2-a) to guarantee the independency of the data as prescribed by the Standard [1]. The height of the anemometers is $0.2 \mathrm{~m}$ above TOR as required by the Standard for the 
Open Field tests, while it is increased to $1.4 \mathrm{~m}$ above TOR for the Open Field (2) tests. Train speed is measured indirectly using photoelectric cells at known distance; temperature and ambient pressure is also measured to monitor ambient conditions. The measurements for all trains were performed with the train running from the right to the left, Train A was measured also in the opposite direction. In these tests the nominal train speed is $300 \mathrm{~km} / \mathrm{h}$, while for Train A, Open Field (2) campaign the nominal speed was $250 \mathrm{~km} / \mathrm{h}$.

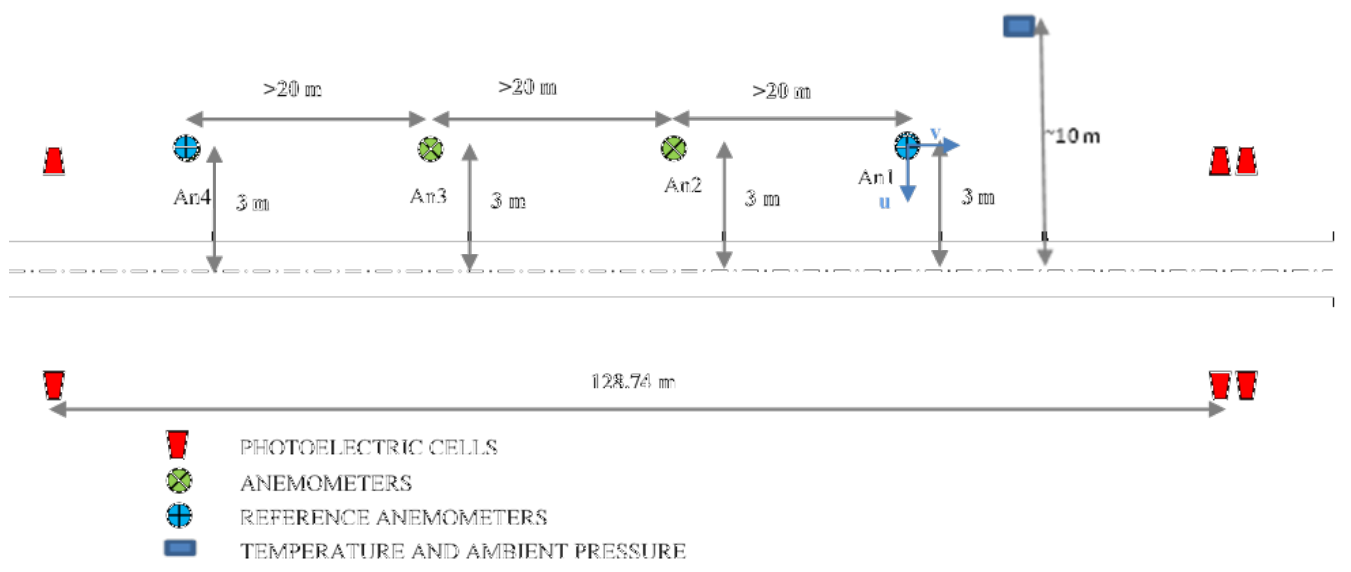

(a)

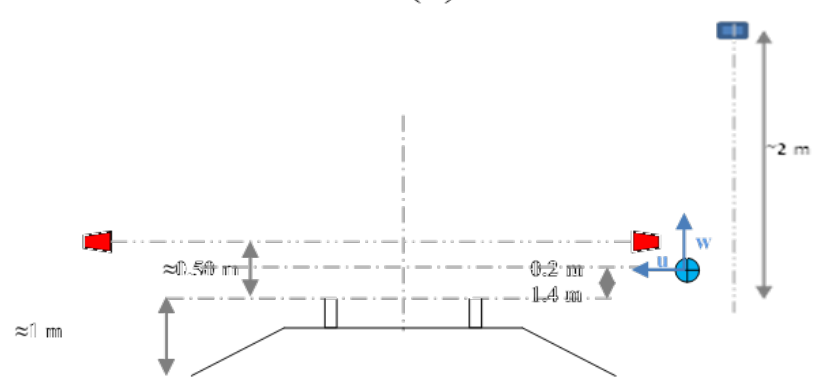

PHOTOELECTRIC CELLS
$\Theta$ ANFMOMETERS
$\theta$ REFERENCE ANEMOMETERS
TEMPERATIRE AND AMBIENT PRESSURE

(b)

Figure 2: Setup of the Open Field and Open Field (2) instrumental campaign.

The experimental Platform measurements were performed in Fiorenzuola station, on the Milano-Bologna line. The setup of the tests can be observed in Figure 3. The setup is compliant with TSI standards [1], with a distance of the first anemometer from the beginning of the standard platform larger than $150 \mathrm{~m}$. It was possible to use 3 anemometers (Gill Instruments Windmaster 1590 pk020) allowing for independent measurements given the distance larger than $20 \mathrm{~m}$; the height of the anemometers is $1.2 \mathrm{~m}$ above the platform and it was possible to measure only one train direction (as can be seen in Figure 3-a) given the non-symmetrical configuration of the test site. 
The train speed is measured indirectly using photoelectric cells at known distance. The nominal speed of the train for these campaign was $200 \mathrm{~km} / \mathrm{h}$.

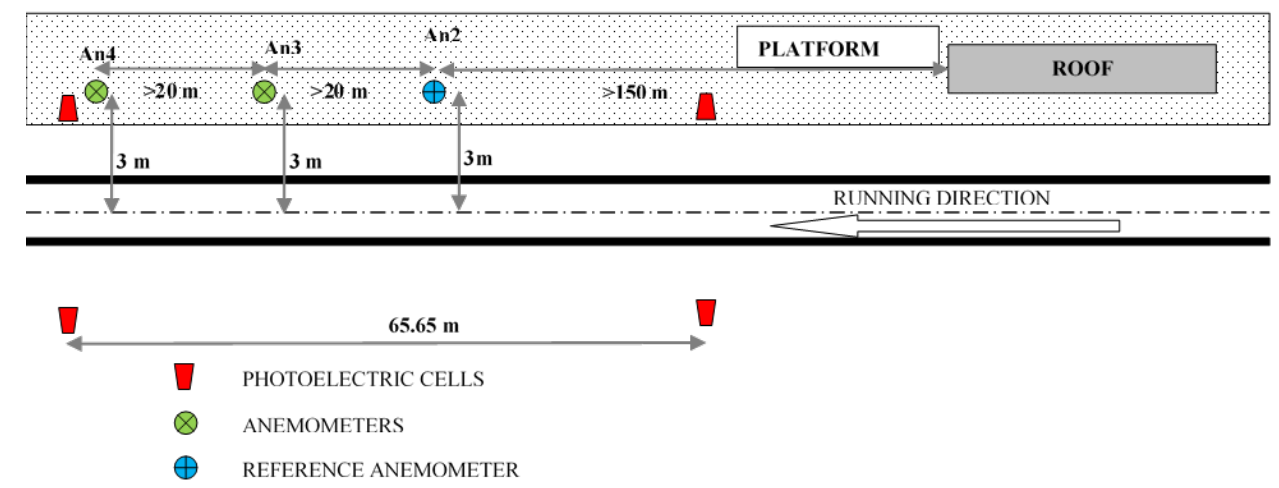

(a)

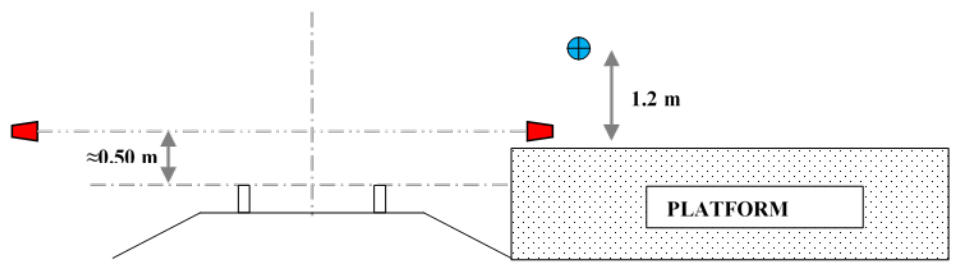

PHOTOELECTRIC CELLS

$\otimes$ ANEMOMETERS

$\oplus$ REFERENCE ANEMOMETER

(b)

Figure 3: Setup of the Platform instrumental campaign.

The slipstream data are analysed in order to allow a direct comparison between the different trains and the different speeds. In particular, all slipstream values are normalized by train speed; the analysis of slipstream time histories is converted in a distribution of slipstream along the space and successively averaging is performed.

\section{Open-field tests}

This section deals with the presentation of the ensemble averages of the train passages collected according to the prescriptions of TSI HS RST Standard [1] in the section "Aerodynamic loads on track workers at the lineside". As reported in the first column of Table 1, data are collected by anemometers placed $0.2 \mathrm{~m}$ above the TOR in an open-field environment. 


\subsection{Transversal and in-line velocity components for Train A}

Figure 4 presents the two horizontal velocity components of the slipstream velocity for Train A. The solid line is the average velocity, the dashed line represents the mean value added and subtracted with the double of the standard deviation.
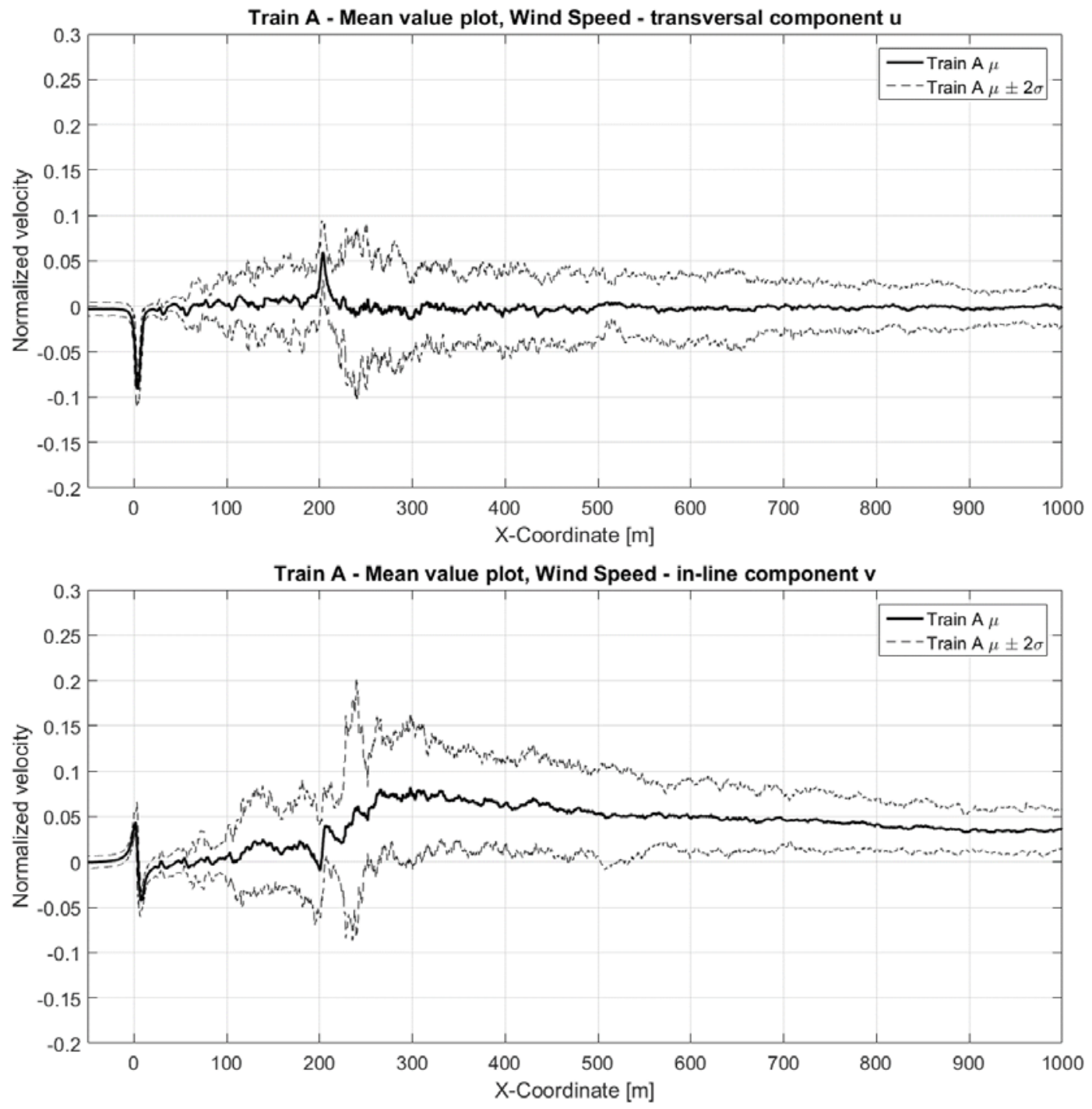

Figure 4: Ensemble mean and standard deviations of in-plane velocity components for Train A.

For what concerns the transversal component $u$, the mean value path shows two opposite peaks in correspondence of the train ends. In the middle, the velocity slightly increases along the train body both in terms of mean and dispersion, but average values are always limited and present small oscillations due to the intercarriages space. As can be seen in the region just behind the tail the wake is 
turbulent. It then dissipates slowly. The first about $50 \mathrm{~m}$ (2 cars) of slipstream show a very low standard deviation, while it increases approaching to the tail of the train reaching its maximum after the train tail passage.

In-line component $v$, depicted in the lowest subfigure of Figure 4, shows essentially higher values than the $u$, exception made for the train ends where the peak of $u$ dominates. In correspondence of the train nose the in-line velocity shows a large deterministic oscillation. After that, the velocity grows very slowly starting from the null value, evidencing small oscillations corresponding to the space between the carriages. As a consequence of the full development of the train boundary layer, the maximum value of $v$ is reached at around the half of the train length. This is confirmed also by the higher value of $\sigma$ reached in this region. The passage of the train tail induces another oscillation of the mean velocity, after which the in-line component increases again. The maximum (less than $10 \%$ of the nominal train speed) is reached about $80 \mathrm{~m}$ behind the tail. In this region the wake developed by the passage of the train is very turbulent and dissipation occurs very slowly: more than $800 \mathrm{~m}$ are needed to reach again the initial value.

\section{2 In-plane slipstream velocity}

Combining the in-line velocity with the transverse slipstream velocity it is possible to present the in-plane slipstream velocity $U$ (required by the standards) of the three high-speed trains is reported in Figure 5.

Scanning the plots from the left to the right, it can be noticed that the influence of the nose shape is very limited as suggested by the amplitude and the wideness of the initial peaks that are very similar for all the trains. As the train nose has passed, the mean velocity increases along the body, but with different slope among the trains. Train $C$ shows a higher rate of growth of velocity probably due to the higher roughness of the train lateral and bottom surfaces. The narrow region (very close to the nose) in which the standard deviation of data for train B is very high is due to the fact that some acquisitions of this vehicle has been collected under environmental wind condition very close to the normative limit, so sometimes the sudden appearance of cross-wind gusts affected the results as can be also appreciated in Figure 6. Moving towards the rear zone of the vehicles, where the boundary layer develops, Train A, as already mentioned, shows a jump of the mean velocity value in the second half of the train body that remains constant until the end of the vehicle. For trains $\mathrm{B}$ and $\mathrm{C}$ the mean velocity increases continuously along the body progressively decreasing the slope, but it is to note that the growth rates are completely different (higher for Train $\mathrm{C}$ than $\mathrm{B}$ ).

After the passage of the train tail, the in-line mean velocity shows some oscillations and generally increases. For Train A and B, the maximum (less than $10 \%$ of the nominal train speed) is reached about $80 \mathrm{~m}$ behind the tail, while for Train $C$ the maximum is much higher (15\% of the nominal speed) and reached $50 \mathrm{~m}$ after the end of the train. This difference can be justified by the sharpness and the slope angle of the train noses and the flow condition. The very turbulent flow for Train $C$ induces a very dissipative wake, so that air speed rapidly decreases, until reaching the same level of other trains. 

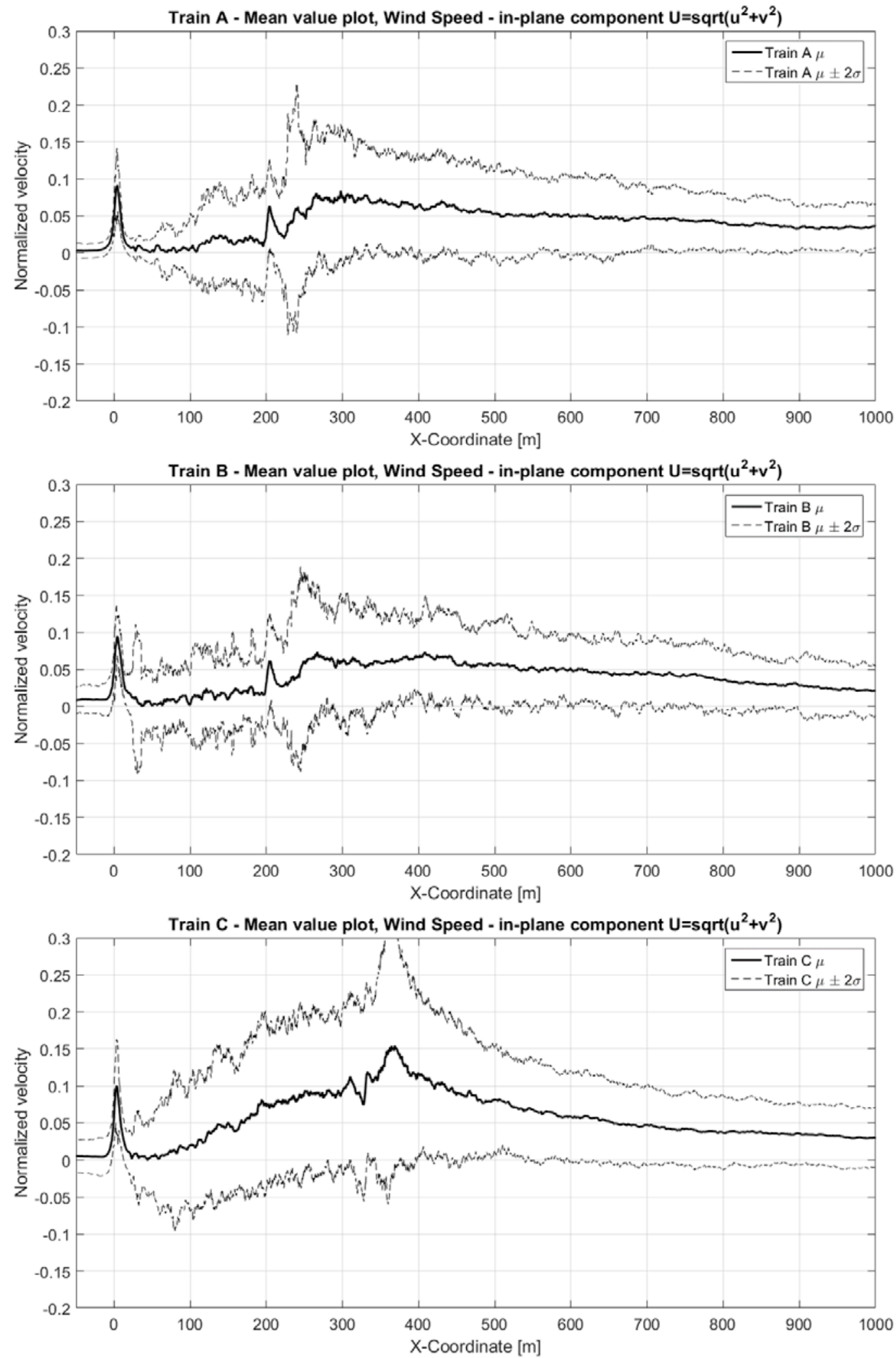

Figure 5: Ensemble averages of slipstream velocity $\mathrm{U}$ for trains $\mathrm{A}, \mathrm{B}$ and $\mathrm{C}$ in open field. 


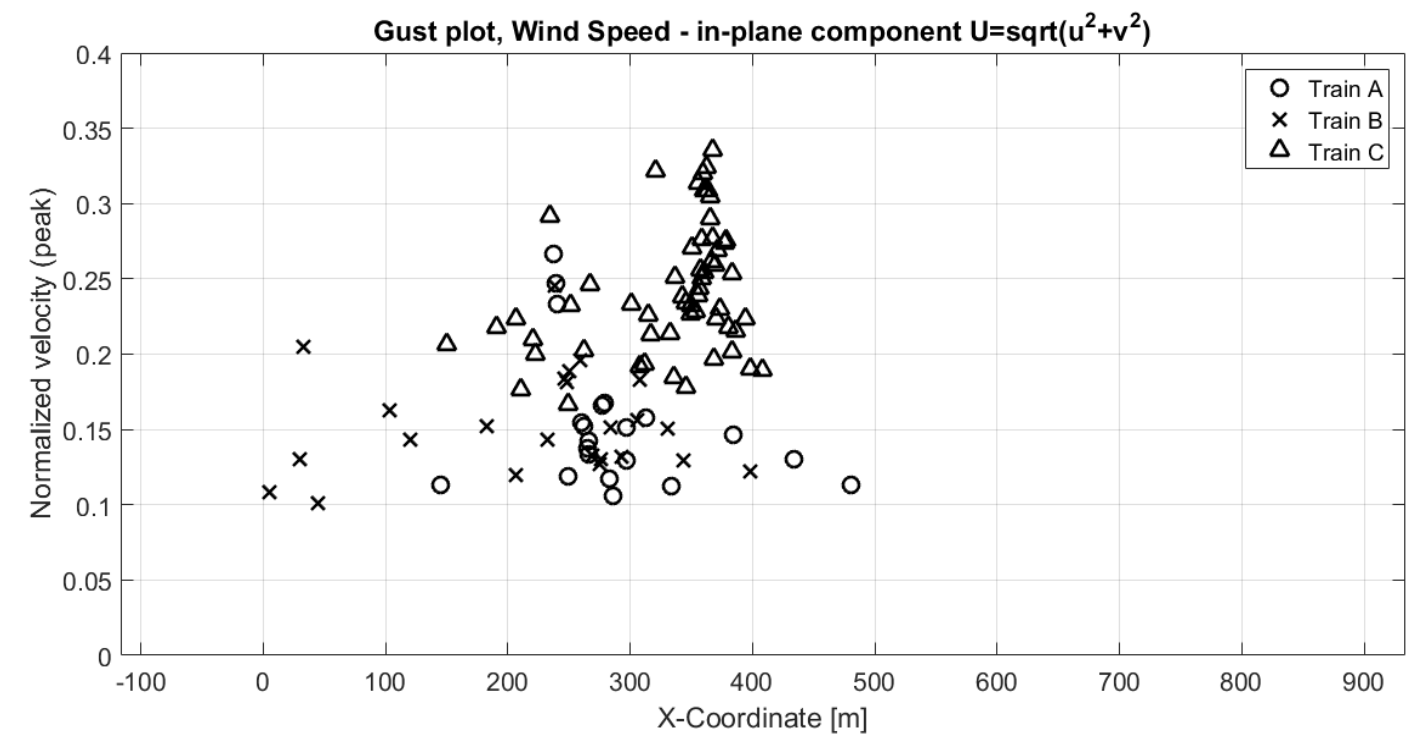

Figure 6: Gust values for Trains A, B and C.

Figure 6 shows the gust (maximum in-plane slipstream value) position and value for each single run of trains $A, B$ and $C$ that composed the dataset analysed in the present section of the paper, while the bar plot of Figure 7 summarizes the gusts in three different classes according to their positions: gusts that occur within the train length constituted the first class, between one time the train length and its double form the second, while the third is the class of the gusts whose position is placed more than two times the length of the trains. The histogram is reported in percentage with respect to the number of the available runs for each considered train. Regarding Train A, they mostly fall in the region just after the train tail, with very few exceptions occurring in the mid-far and far wake region. Train B shows high dispersions of the data along the train length (X-Coordinate): maximum values of slipstream velocity are gathered again in the near wake region, but also some extreme peak locations are visible in the region close to the train nose. These are relative to the some records of particular windy days, that slightly afflicted test results. In Figure 6, watching at Train $\mathrm{C}$, it is recognizable that the gusts are deterministically placed at $x$ equal to about $370 \mathrm{~m}$ (i.e. close to the train tail), but peak magnitudes are widespread along the vertical axis, reaching extreme values significantly higher than other trains. From the bar plot of Figure 7, it is visible a not negligible quantity of gusts that befall within the train length, partially justifiable with the adverse weather conditions of the test days.

There is a positive correlation among the information contained in Figure 5 and Figures 6 and 7. For example, it can be observed that the low variability and limited amplitude of the slipstream velocity of Train A for values of the X-Coordinate that belong to the first class in Figure 5, it is confirmed by the quasi-absence of the gusts in the same region, as shown both by the gust plot and its position histogram. Similarly, the good correlation can be also qualitatively worked out looking at the maximum value reached by the $\mu+2 \sigma$ curve of Train $C$ in Figure 5 and the gust dispersion clearly visible in each single runs showed in Figure 6. 


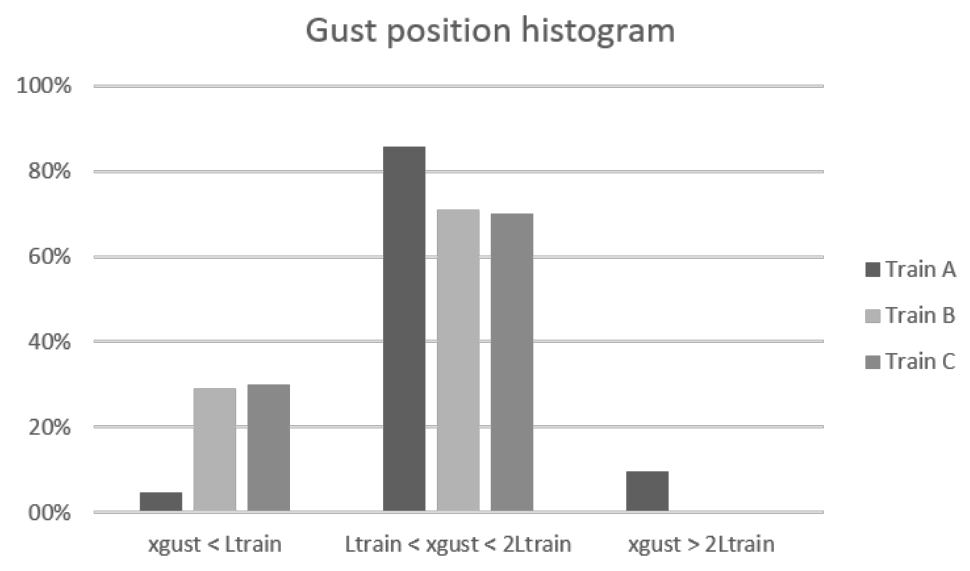

Figure 7: Bar plot of the gust positions for Trains A, B and C.

\section{Comparison between measurements taken at different heights}

In this section, data coming from the previous one are compared to other measurements taken in the same open-field test site, but in a successive test campaign where the anemometers were placed $1.4 \mathrm{~m}$ above the TOR, instead of the original $0.2 \mathrm{~m}$. Figure 8 shows the horizontal-plane slipstream velocities for all the trains, both in terms of the mean value $\mu$ and $\mu \pm 2 \sigma$ (mean value plus or minus two times the standard deviation), for the two heights.

Slipstream mean values for Train A are initially superposed, while in the second half of the train the lower anemometers recorded the limited jump in the slipstream velocity value, the higher ones a significant increase of it. Moreover, the peak associated to the train tail is higher in the case of measurements taken at $1.4 \mathrm{~m}$. After the passage of the train, the air velocity increases in the lower region, reaching the same value of the higher. Once the curves overlap again, the decay is very similar.

Train B shows a behaviour similar to the one of Train A, i.e. very similar velocity values until the anemometers entered in the boundary layer. From this point, the velocity measured by the higher anemometers is higher than the one measured by the lower. In the near wake region, the air velocity increases only at the lower height. Then, despite the height, the behaviour is similar.

Turning to Train C, it is very surprising to observe an inverted general trend: higher velocities are not associated at higher anemometers, but it is the contrary. In particular, it is recognizable the different rate of growth of the slipstream velocity along the train body with respect to the height.

Train C measurements are well aligned with the ones showed in [5], where, with respect to the Spanish high-speed train AVE S-100, it is affirmed that the higher values of velocity recorded at the lower height are probably due to the body configuration or the wedge-like front of the train.

Evidences coming from the present work suggests that the detected opposite behaviour of trains $\mathrm{A}$ and $\mathrm{B}$ with respect to $\mathrm{C}$ or other previous works can be justified by the particular attention given to the aerodynamic optimization of the bogies of new generation high-speed trains. 

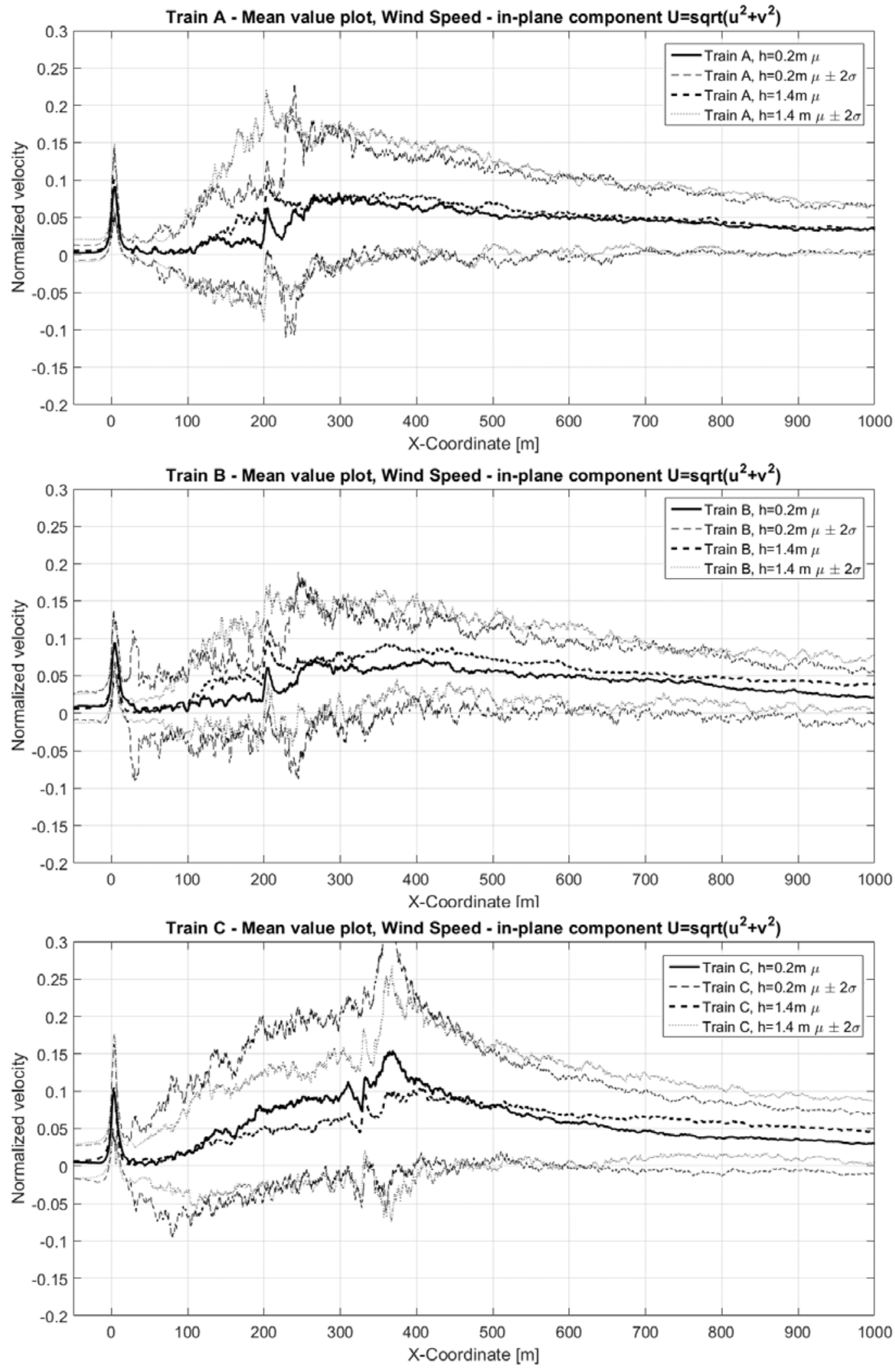

Figure 8: Ensemble averages of slipstream velocity $\mathrm{U}$ for trains A, B and C in openfield for different anemometer heights. 


\section{Effect of the platform}

Figures 9 and 10 show the ensemble slipstream velocities for trains A and B in two subplots, the higher relative to the data recorded at the platform, while the lower at the trackside. In both cases the anemometers height is around $1.4 \mathrm{~m}$ with respect to the TOR, as already specified in Table 1 , while the platform height is $0.25 \mathrm{~m}$.
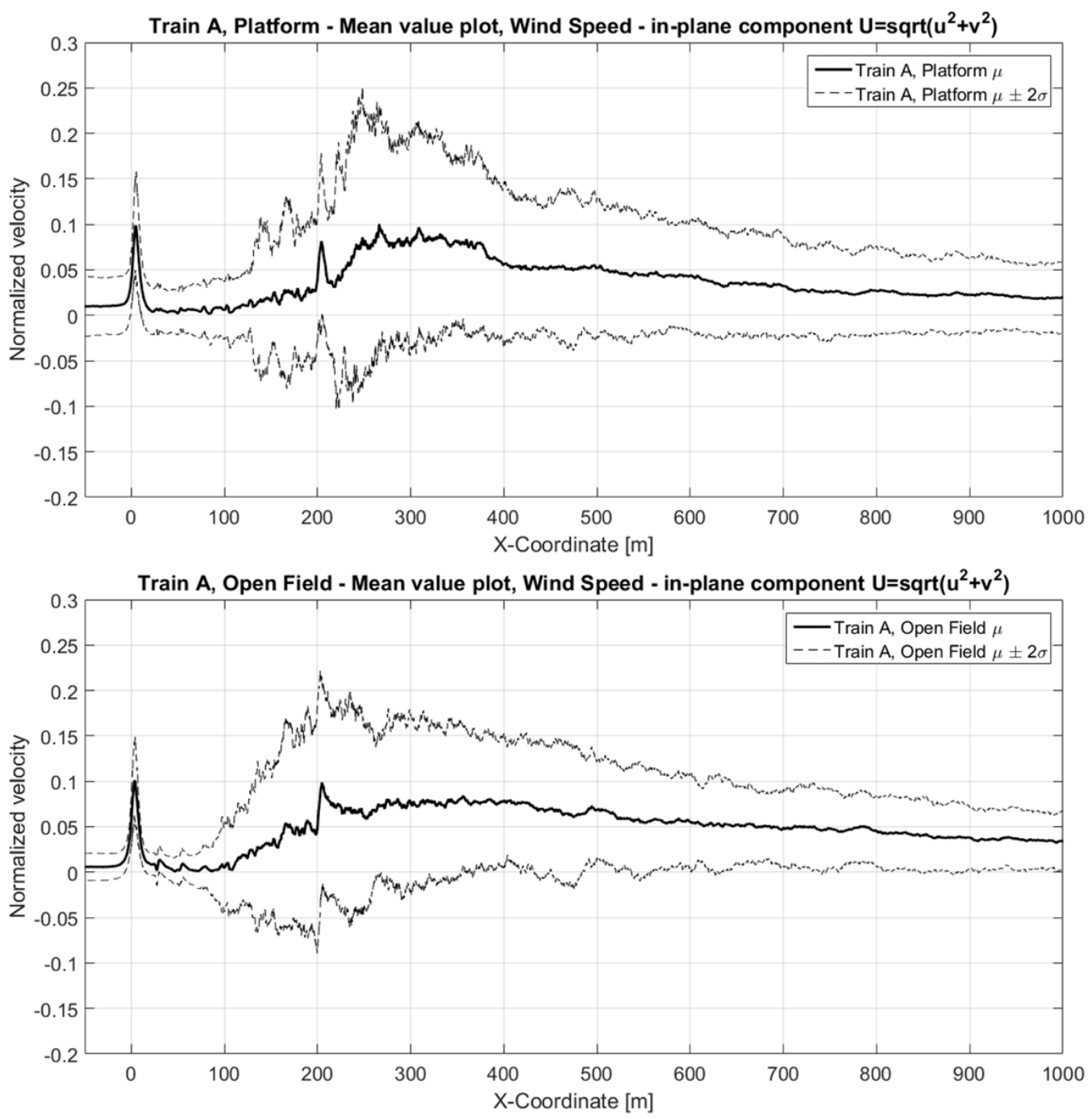

Figure 9: Ensemble averages of slipstream velocity $U$ for trains $A$, above at platform test-site, below in open field (2). Anemometers height equal to $1.4 \mathrm{~m}$ with respect to the TOR.

Comparing platform and open-field measurements for each train interesting difference are appreciable for $x$ greater than $100 \mathrm{~m}$. Due to the presence of the platform, the lateral expansion of the boundary layer is bounded preventing the growth of the transversal velocity component $v$. In fact, in correspondence of the train tail ( $x$ equal to 200m), the second deterministic peak of the in-line component of the slipstream velocity is clearly visible (more than in the case of trackside). Once 
the train has moved away, the wake develops very quickly and the slipstream velocity reaches its maximum value that is almost $10 \%$ of the train speed, slightly higher than the open-field one. Then, slipstream air velocity starts to decrease: the ensemble mean of open-field tests shows a linear decay, while in the case of the platform measurements there is a sudden drop down for $x$ equal to $380 \mathrm{~m}$, that does not influence the general trend, but creates a sort of offsets between the two test environments.
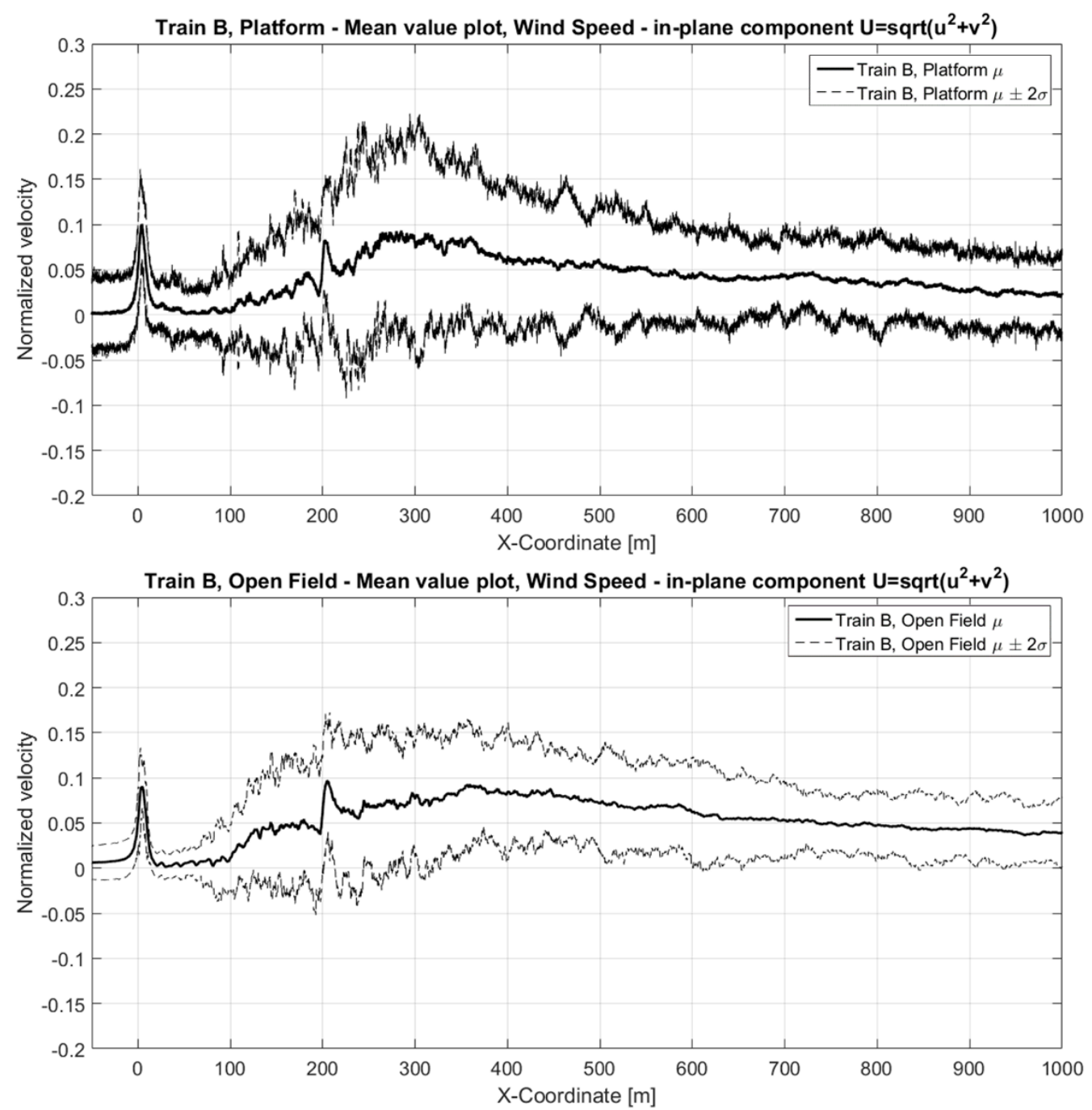

Figure 10: Ensemble averages of slipstream velocity $U$ for trains $B$, above at platform test-site, below in open field. Anemometers height equal to 1.4 $\mathrm{m}$ with respect to the TOR.

Figures 11 and 12 replicate the figures 6 and 7 shown in Section 3. Figure 11 shows the position and the value of the gusts of each run componing the four ensembles presented in this section, while Figure 12 groups the gusts into three classes function of the X-Coordinate. Gusts at platform are generally higher than at trackside and moreover they occur in the near wake region, as a consequence of the forced evolution of the wake confined by the platform itself. 


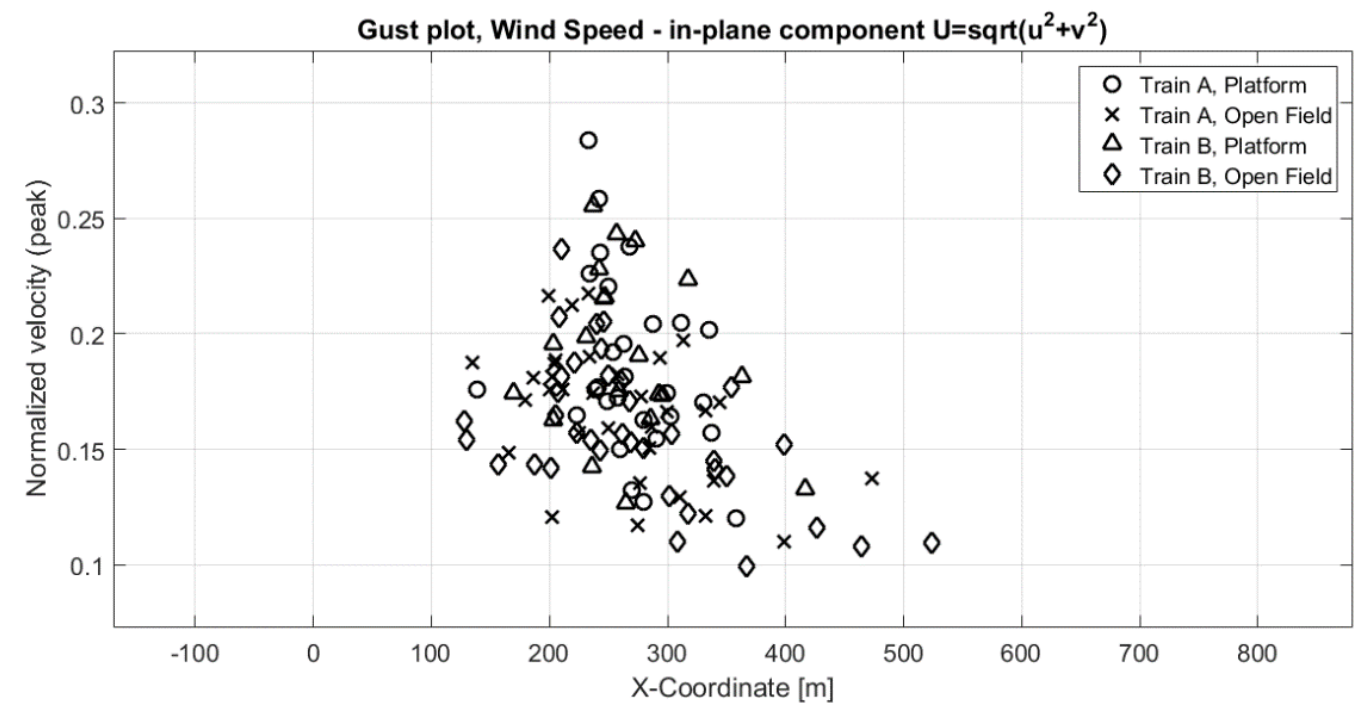

Figure 11: Gust values for Trains $\mathrm{A}$ and $\mathrm{B}$ at platform and in open field environments.

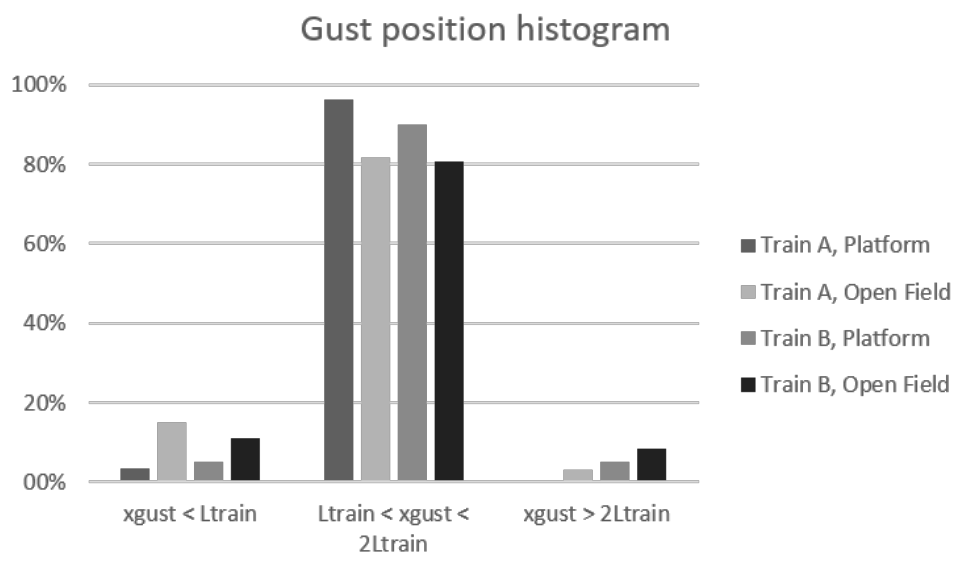

Figure 12: Bar plot of the gust positions for Trains A and B at platform and in open field environments.

Anyway, the differences are always limited and computing the slipstream gust values following TSI [1] recommendation, it is possible to obtain the $U_{\text {TSI }}$ values reported in Table 2 for the two trains. It shows that carrying out tests at the platform or at the trackside is equivalent, as already noticed in [6], suggesting "that platform tests may not be required in the TSI methodology”.

\begin{tabular}{|c|c|c|c|c|c|c|}
\hline Test site & \multicolumn{3}{|c|}{ Open Field (h=1.4 m) } & \multicolumn{3}{c|}{ Platform } \\
\hline $\begin{array}{c}\text { Normalized } \\
\text { velocity }\end{array}$ & Mean $\bar{v}$ & $\begin{array}{c}\text { Std. Dev. } \\
\sigma_{u}\end{array}$ & $\begin{array}{c}U_{T S I} \\
\bar{v}+2 \sigma_{u}\end{array}$ & Mean $\bar{v}$ & $\begin{array}{c}\text { Std. Dev. } \\
\sigma_{u}\end{array}$ & $\begin{array}{c}U_{T S I} \\
\bar{v}+2 \sigma_{u}\end{array}$ \\
\hline Train A & 0.107 & 0.022 & 0.151 & 0.109 & 0.025 & 0.161 \\
\hline Train B & 0.106 & 0.018 & 0.141 & 0.117 & 0.028 & 0.172 \\
\hline
\end{tabular}

Table 2: $\mathrm{U}_{\mathrm{TSI}}$ values for the Open Field (2) and Platform measurements. 


\section{Conclusions}

The presented work put in evidence some conclusions that are organized as in the following.

1) Watching at the single slipstream velocity components $u$ and $v$ it is clear that transversal component $v$ generally dominates. Peaks of $u$ are visible and important only in the regions close to the train ends, while $v$ continues to grow also some meters after the passage of the train.

2) The slipstream velocity magnitude increases along the train side and depends to its superficial roughness. The growth rate of slipstream velocity increases in the second half of the train body as a consequence of the full development of the vehicle boundary layer and reaches the maximum value after the train passage.

3) Open-field measurements taken at different heights show strong differences among the trains. As a general conclusion, it can be affirmed that older trains have a different behavior with respect to the new-generation high-speed trains: this can be imputed to the particular attention that has been dedicated to the aerodynamic performance of the whole train, in particular to the bogie fairings and intercar gaps, generating slipstream velocities higher at superior heigths.

4) The deep analysis of open-field and platform measurements taken at the same height with respect to the TOR, evidences some difference between the tests, that are related to the costraints that prevent the wake to freely develop laterally when the platform is present. However the statical synthetic data $\bar{v}+$ $2 \sigma_{u}$ evaluated according to the TSI standard are very similar for the two test sites and suggest that it is possible to propose a revision of the TSI homologation methodology, dismissing the need to perform tests on platforms.

The presented data compose also a useful database that can be used to validate numerical models, to be performed as a step forward of this work. Once validated, these numerical models should let the researchers to have a better understanding about the train features that are more influent on train aerodynamics.

\section{References}

[1] European Rail Agency TSI Technical Specification for interoperability Rolling stock sub-system [Book]. - [s.l.] : Directive 96/48/EC, 2008.

[2] Hemida H. Krajnović S. LES study of the influence of the nose shape and yaw angles on flow structures around trains // Journal of Wind Engineering and Industrial Aerodynamics. - 2008. - Vol. 98 (1). - p. 34-46.

[3] Hemida H. Baker C., Gao G. The calculation of train slipstreams using largeeddy simulation // Proceedings of the Institution of Mechanical Engineers, Part F: Journal of Rail and Rapid Transit. - 2014. - Vol. 228(1). - p. 25-36. 
[4] Zhang J. Gao G., Huang S., Liu T. Effect on measurements of anemometers due to a passing high-speed train // Wind and Structures, An International Journal. - 2015. - Vol. 20 (4). - p. 549-564.

[5] Baker C.J. Quinn A., Sima M., Hoefener L., Licciardello R. Full-scale measurement and analysis of train slipstreams and wakes. Part 1: Ensemble averages // Proceedings of the Institution of Mechanical Engineers, Part F: Journal of Rail and Rapid Transit. - 2014. - Vol. 228 (5). - p. 451-467.

[6] Baker C.J. Quinn A., Sima M., Hoefener L., Licciardello R. Full-scale measurement and analysis of train slipstreams and wakes. Part 2 Gust analysis // Proceedings of the Institution of Mechanical Engineers, Part F: Journal of Rail and Rapid Transit. - 2014. - Vol. 228 (5). - p. 468-480.

[7] Sterling M. Baker C.J., Jordan S.C., Johnson T. A study of the slipstreams of high-speed passenger trains and freight trains // Proceedings of the Institution of Mechanical Engineers, Part F: Journal of Rail and Rapid Transit. - 2008. 2 : Vol. 222. - p. 177-193.

[8] Bell J.R. Burton D., Thompson M., Herbst A., Sheridan J. Wind tunnel analysis of the slipstream and wake of a high-speed train // Journal of Wind Engineering and Industrial Aerodynamics. - 2014. - Vol. 134 (1). - p. 122-138.

[9] Bell J.R. Burton D., Thompson M.C., Herbst A.H., Sheridan J. Moving model analysis of the slipstream and wake of a high-speed train // Journal of Wind Engineering and Industrial Aerodynamics. - 2015. - Vol. 136. - p. 127-137.

[10] Gil N Baker CJ and Roberts C. The measurement of train slipstream characteristics using a rotating rail rig. // Proceedings of the BBAA sixth international colloquium on bluff bodies aerodynamics \& applications, Milano, Italy, 20-24 July. - 2008. 